\title{
Identification of novel and recurrent glucokinase mutations in Belgian and Luxembourg maturity onset diabetes of the young patients
}

\section{To the Editor:}

Maturity onset diabetes of the young (MODY) is a monogenic form of diabetes mellitus accounting for approximately $1-2 \%$ of noninsulin dependent diabetes. It is characterized by early-onset pancreatic $\beta$-cell dysfunction and autosomal dominant inheritance. MODY is a genetic heterogeneous condition for which today seven causal genes have been identified; the hepatocyte nuclear factor $4 \alpha(H N F-4 \alpha)$ causing MODY1 (1), the glucokinase enzyme $(G C K)$ responsible for MODY2 (2), the hepatocyte nuclear factor $1 \alpha(H N F-1 \alpha$ or $T C F 1)$ causing MODY3 (3), insulin promotor factor-1 (IPF1; MODY4) (4), transcription factor HNF$1 \beta$ (TCF2; MODY5) (5), NeurolD (MODY6) (6) and the carboxyl ester lipase $(C E L)$ gene (7). In Europe, GCK-MODY and HNF-1 $\alpha$-MODY are the most prevalent forms (8-11), with their prevalence mainly depending on the way of recruitment.

We have performed molecular screening of the $G C K$ gene in 161 patients belonging to 124 families, referred to our centre between 2002 and 2005 from hospitals in Belgium and Luxembourg. All probands fulfilled at least two of the following criteria: early-onset hyperglycaemia (age of onset $<40$ years), the absence of beta cell autoantibodies and a positive familial history for diabetes, with at least two successive generations affected.

Polymerase chain reaction amplification (primers and conditions available upon request) and sequence analysis of exon 1a and exons 2 to 10 of the $G C K$ gene (Genbank XM_041001) resulted in the detection of a mutation in 33 of the 124 probands. Additional mutation analysis performed in available family members of the probands showed cosegregation of the $G C K$ mutations, with the MODY phenotype examined in all the families.
19 different mutations were identified (Table 1), including eight previously described missense mutations: p.Arg36Trp (12), p.Cys129Tyr (9), p.Arg191Trp (13), p.Gly223Ser (9), p.Val226Met (14), p.Ala378Thr (15), p.Ser441Trp (9) and p.Arg447Gln (15). Three of the 11 new $G C K$ mutations identified during this study are clearly inactivating, as they result in pre-mature termination of translation: c.171delG, c.663673dupGGTCGGCATGA and c.1261delG cause pre-mature termination codons after respectively 85, 227 and 429 amino acids. Two splice site mutations (680-1 $\mathrm{G}>\mathrm{A}$ and 680-6 $\mathrm{C}>\mathrm{A})$ may also result in aberrant nonfunctional $G C K$ transcripts as theoretical splice site prediction (16) shows decrease in splice acceptor consensus value for both 680-1 $\mathrm{C}>\mathrm{A}$ (from 0.869 to 0.662 ) and $680-6 \mathrm{C}>\mathrm{A}$ (from 0.869 to 0.801 ) mutations. Unfortunately, no RNA was available to confirm this. Six new missense mutations (p.Phe152Leu, p.Ala188Val, p.Met202Arg, p.Asn231His, p.Leu315Phe and p.Cys434Phe) were detected in diabetic probands and were found to be absent in our control population (100 chromosomes, Belgian origin). All six missense mutations were predicted pathogenic by the theoretical prediction programme SIFT (17), while the Polyphen theoretical prediction programme (18) predicts a damaging effect for four of them, but not for p.Ala188Val and p.Leu315Phe. However, these two mutations segregate with diabetes in the families tested and are highly conserved in the glucokinases or hexokinases of all the mammalians. Moreover, mutations affecting the alanine 188 residue have been reported in diabetic patients before $(19,20)$. The same is true for the cysteine residue at position $434(10,20)$. The p.Phe152Leu and p.Asn231His missense mutations contribute to the glucose binding site and are believed to disrupt glucose binding. 


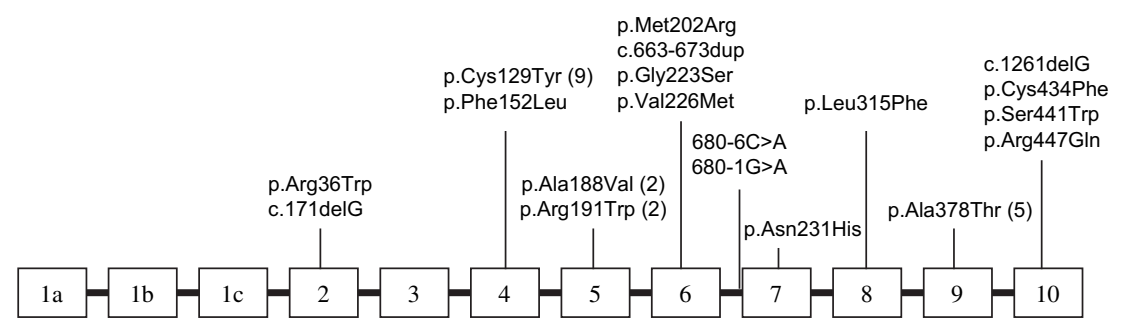

Fig. 1. Mutation distribution of glucokinase enzyme mutations found in Belgium and Luxembourg. If a mutation was found in multiple families the exact number is given in parentheses.

Four mutations were detected in more than one proband; p.Cys129Tyr in nine probands, p.Ala378Thr in five probands and p.Ala188Val and p.Arg191Trp in two probands each. Together, p.Cys129Tyr and p.Ala378Thr represented $42.4 \%$ of the $G C K$ mutations identified in our GCK-MODY population. All the probands harbouring the p.Ala378Thr mutation originated from the Belgian province of West-Flanders, suggesting a founder mutation with a common ancestor from this region. Additional genealogical research and haplotype analysis, with polymorphic markers flanking the $G C K$ gene (D7S2541; 40.5 Mb, D7S691; 41.8 $\mathrm{Mb}$ and D7S2506; $47.5 \mathrm{Mb}$ ) could confirm this for 3 of the 5 families showing this mutation (families 8 , 16 and 23). In five families with p.Cys129Tyr, a possible common haplotype could be found for distal-flanking markers D7S2541 and D7S691, but due to the low number of available affected persons in all the families with this mutation, the overall results were inconclusive. Haplotype analysis showed a common specific haplotype for markers D7S2541, D7S691 and D7S2506 segregating with the p.Ala188Val mutation in the two families with this mutation. Previously, a founder effect for another GCK missense mutation (p.Gly299Arg) has been demonstrated in the Oxford region (UK), but such regional clustering is rather the exception as in most populations a variety of mutations scattered all over the $G C K$ gene is identified $(9-11,14,15,20)$.

MODY is defined as an autosomal dominant form of diabetes mellitus, with an early onset, usually before 25 years. However, there are several MODY subtypes with different clinical characteristics. The GCK-MODY phenotype is normally characterized by mild nonprogressive hyperglycaemia present at very young age (21), and GCK-MODY patients rarely develop diabetesassociated complications $(14,21,22)$. Also, in our GCK-MODY probands, there was mostly mild, nonprogressive hyperglycaemia (mean of fasting glucose $7.0 \pm 1.2 \mathrm{mmol} / \mathrm{l} ; n=30$ ) and $88 \%$ of the probands showed elevated haemo- globin A1c (Table 1). However, we could not detect a clear correlation between nature of the mutation and therapy (insulin/oral hypoglycaemic agents/diet), with different therapies effective for different patients with the same mutation. This may be explained by different attitudes of the treating physicians towards therapy, but may also be caused by additional factors influencing disease expression. The latter is illustrated by proband MODY32 who showed glucose levels up to $50 \mathrm{mmol} / 1$, especially in times of infection, and required insulin therapy combined with diet. Analysis of all coding $G C K$ exons showed only a heterozygous p.Arg191Trp mutation and no homozygosity or compound heterozygosity, which would have been compatible with permanent neonatal diabetes mellitus (PNDM). Possibly, this patient has both GCK-MODY and an additional type of diabetes.

Because of the usually mild phenotype GCKMODY patients are often only detected during routine screenings such those during pregnancy for women. It is therefore not surprising that a significant number of female patients with a $G C K$ mutation are classified as having gestational diabetes mellitus (13). Consequently, the age of diagnosis in GCK-MODY patients does not often reflect the real age of onset. Therefore, we preferred also to include in our GCK-MODY screening patients with older age of diagnosis, if they fulfilled the other criteria. In our $G C K$ positive probands, the mean age of diagnosis was 18 , with 29 of them diagnosed before the age of 40. Four patients were diagnosed between the age of 40 and 60. This indeed illustrates that the cut-off age of diagnosis should not be set too stringent for $G C K$ screening.

$G C K$ mutations account for the majority of mutations identified in various European MODY populations (9-11), while in other countries such as the UK, GCK-MODY is reported as the second most prevalent form of MODY after HNF-1 $\alpha$-MODY (8). This difference is mainly explained by the way of recruitment. Indeed, recruitment in adult clinics 
Letter to the Editor

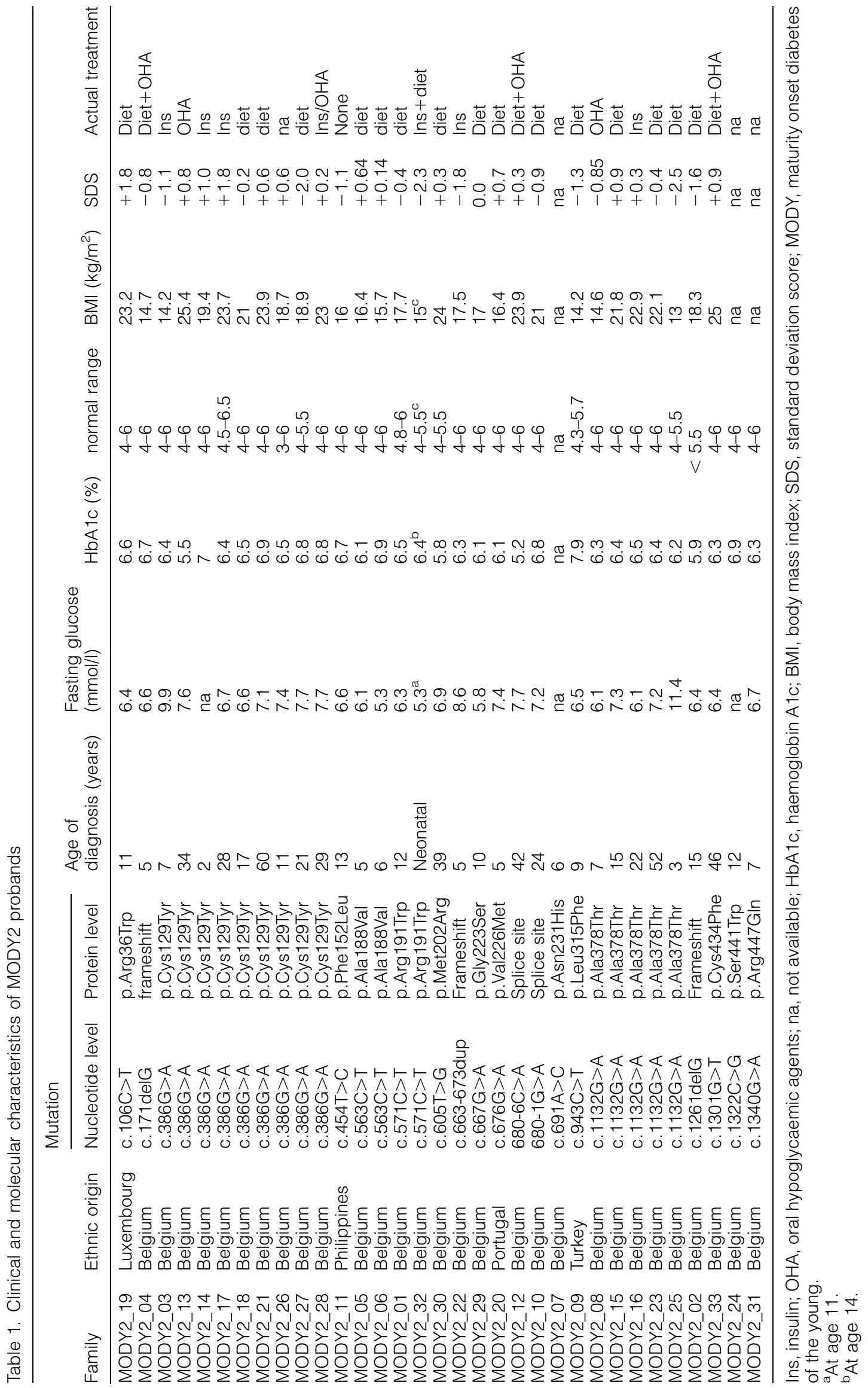


seems to correlate with higher frequency of HNF-1 $\alpha$-MODY positive patients, while GCKMODY seems to be the most frequent form in paediatric MODY populations (17, 23-25). This can partially be explained by the observation that GCK-MODY patients often do not continue their medical follow up in adulthood, because often their hyperglycaemia is well under control by diet alone. Our study recruited both in paediatric and adult clinics, and in $26.6 \%$ of the 124 probands, a $G C K$ mutation was detected. This frequency is comparable with frequencies reported in Germany (22.5\%) (11) and Czech republic $(31 \%)(10)$, but lower than the $41 \%$ frequency observed in paediatric populations in Spain (23) and Italy (9). This difference may partially be explained by the less stringent inclusion criteria with regard to age of diagnosis we used.

In conclusion, we show that $G C K$ mutations are a frequent cause of MODY presentation in Belgium and Luxembourg, with the p.Cys129Tyr and p.Ala378Thr being most prevalent. Further studies are now needed to determine the prevalence of other MODY types in our population.

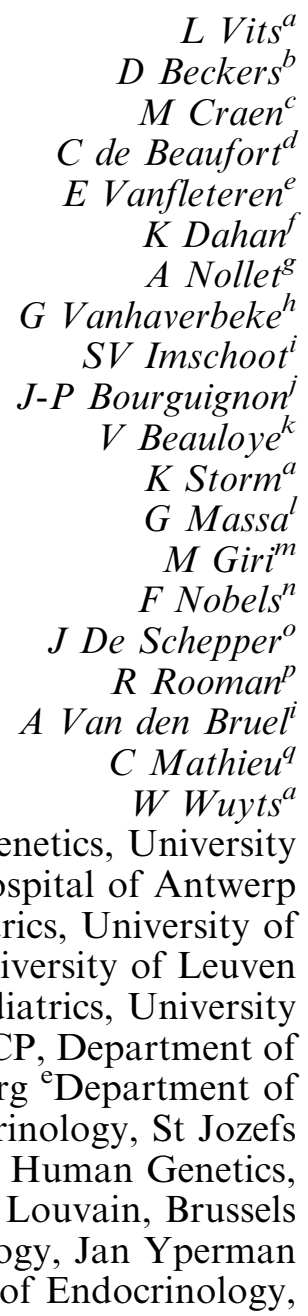

AZ Groeninge Kortrijk, Kortrijk ${ }^{\mathrm{i}}$ Department of Internal Medicine and Endocrinology, Algemeen Ziekenhuis Sint Jan, Brugge ${ }^{\mathrm{j}}$ Department of Paediatrics, University of Liege, Liege

${ }^{\mathrm{k}}$ Department of Paediatrics, Cliniques Universitaires St-Luc, Brussels ${ }^{1}$ Department of Paediatrics, Virga Jesseziekenhuis, Hasselt ${ }^{\mathrm{m}}$ Department of Endocrinology, University

Hospital Gent, Gent ${ }^{\mathrm{n}}$ Department of Endocrinology, OLV-Ziekenhuis, Aalst ${ }^{\circ}$ Department of Paediatrics, Academic Hospital V.U.B., Brussels ${ }^{\mathrm{p}}$ Department of Paediatrics, University Hospital of Antwerp, Antwerp ${ }^{\mathrm{q}}$ Department of Endocrinology, University of Leuven (KUL), Leuven, Belgium

\section{References}

1. Yamagata K, Furuta H, Oda $\mathrm{N}$ et al. Mutations in the hepatocyte nuclear factor-4alpha gene in maturity-onset diabetes of the young (MODY1). Nature 1996: 384: 458460 .

2. Froguel P, Zouali H, Vionnet $\mathrm{N}$ et al. Familial hyperglycemia due to mutations in glucokinase - definition of a subtype of diabetes mellitus. N Engl J Med 1993: 328: 697-702.

3. Yamagata K, Oda N, Kaisaki PJ et al. Mutations in the hepatocyte nuclear factor-1alpha gene in maturity-onset diabetes of the young (MODY3). Nature 1996: 384: 455458.

4. Stoffers DA, Ferrer J, Clarke WL, Habener JF. Early-onset type-II diabetes mellitus (MODY4) linked to IPF1. Nat Genet 1997: 17: 138-139.

5. Horikawa $\mathrm{Y}$, Iwasaki $\mathrm{N}$, Hara $\mathrm{M}$ et al. Mutation in hepatocyte nuclear factor-1 beta gene (TCF2) associated with MODY. Nat Genet 1997: 17: 384-385.

6. Malecki MT, Jhala US, Antonellis A et al. Mutations in NEUROD1 are associated with the development of type 2 diabetes mellitus. Nat Genet 1999: 23: 323-328.

7. Raeder H, Johansson S, Holm PI et al. Mutations in the CEL VNTR cause a syndrome of diabetes and pancreatic exocrine dysfunction. Nat Genet 2006: 38: 54-62.

8. Frayling TM, Evans JC, Bulman MP et al. Beta-cell genes and diabetes: molecular and clinical characterization of mutations in transcription factors. Diabetes 2001: 50 (Suppl. 1): S94-100.

9. Massa O, Meschi F, Cuesta-Munoz A et al. High prevalence of glucokinase mutations in Italian children with MODY. Influence on glucose tolerance, first-phase insulin response, insulin sensitivity and BMI. Diabetes Study Group of the Italian Society of Paediatric Endocrinology and Diabetes (SIEDP). Diabetologia 2001: 44: 898905.

10. Pruhova S, Ek J, Lebl $\mathbf{J}$ et al. Genetic epidemiology of MODY in the Czech republic: new mutations in the MODY genes HNF-4alpha, GCK and HNF-1alpha. Diabetologia 2003: 46: 291-295.

11. Toaima D, Nake A, Wendenburg $\mathbf{J}$ et al. Identification of novel GCK and HNF1A/TCF1 mutations and polymorphisms in German families with maturity-onset diabetes of the young (MODY). Hum Mutat 2005: 25: 503-504.

12. Hager $J$, Blanche $H$, Sun $F$ et al. Six mutations in the glucokinase gene identified in MODY by using a 
nonradioactive sensitive screening technique. Diabetes 1994: 43: 730-733.

13. Ellard S, Beards F, Allen LI et al. A high prevalence of glucokinase mutations in gestational diabetic subjects selected by clinical criteria. Diabetologia 2000: 43: 250-253.

14. Velho $\mathrm{G}$, Blanche $\mathrm{H}$, Vaxillaire $\mathrm{M}$ et al. Identification of 14 new glucokinase mutations and description of the clinical profile of 42 MODY-2 families. Diabetologia 1997: 40: 217-224.

15. Thomson KL, Gloyn AL, Colclough $\mathrm{K}$ et al. Identification of 21 novel glucokinase (GCK) mutations in UK and European Caucasians with maturity-onset diabetes of the young (MODY). Hum Mutat 2003: 22: 417.

16. Krawczak M, Reiss J, Cooper DN. The mutational spectrum of single base-pair substitutions in mRNA splice junctions of human genes: causes and consequences. Hum Genet 1992: 90: 41-54.

17. Costa A, Bescos M, Velho $G$ et al. Genetic and clinical characterisation of maturity-onset diabetes of the young in Spanish families. Eur J Endocrinol 2000: 142: 380-386.

18. Sunyaev S, Ramensky V, Koch I, Lathe W III, Kondrashov AS., Bork P Prediction of deleterious human alleles. Hum Mol Genet 2001: 10: 591-597.

19. Shimada F, Makino H, Hashimoto $\mathrm{N}$ et al. Type 2 (noninsulin-dependent) diabetes mellitus associated with a mutation of the glucokinase gene in a Japanese family. Diabetologia 1993: 36: 433-437.

20. Gloyn AL. Glucokinase (GCK) mutations in hyper- and hypoglycemia: maturity-onset diabetes of the young, permanent neonatal diabetes, and hyperinsulinemia of infancy. Hum Mutat 2003: 22: 353-362.

21. Pearson ER, Velho G, Clark P et al. beta-cell genes and diabetes: quantitative and qualitative differences in the pathophysiology of hepatic nuclear factor-1alpha and glucokinase mutations. Diabetes 2001: 50 (Suppl. 1): S101-107.

22. Stride A, Vaxillaire $M$, Tuomi $T$ et al. The genetic abnormality in the beta cell determines the response to an oral glucose load. Diabetologia 2002: 45: 427-435.

23. Barrio R, Bellanne-Chantelot C, Moreno JC et al. Nine novel mutations in maturity-onset diabetes of the young (MODY) candidate genes in 22 Spanish families. J Clin Endocrinol Metab 2002: 87: 2532-2539.

24. Frayling TM, Bulamn MP, Ellard S et al. Mutations in the hepatocyte nuclear factor-1alpha gene are a common cause of maturity-onset diabetes of the young in the U.K. Diabetes 1997: 46: 720-725.

25. Ziemssen F, Bellanne-Chantelot C, Osterhoff M, Schatz H, Pfeiffer AF. To: Lindner T, Cockburn BN, Bell GI (1999). Molecular genetics of MODY in Germany. Diabetologia 42: 121-123. Diabetologia 2002: 45: 286-287; author reply 287-288.

Correspondence:

Wim Wuyts, $\mathrm{PhD}$

Department of Medical Genetics University and University

Hospital of Antwerp

Universiteitsplein 1

2610 Antwerp Belgium

Tel.: 323820.25 .70

Fax: 323820.25 .66

e-mail:wim.wuyts@ua.ac.be 